\title{
PENGARUH SIKLUS HIDUP PERUSAHAAN DAN UKURAN PERUSAHAAN TERHADAP MANAJEMEN LABA
}

\author{
Erna Niayati Dewiningsih ${ }^{1}$, Gustita Arnawati Putri² \& Ardian Prima Putra ${ }^{3}$ \\ ${ }^{123}$ Universitas Veteran Bangun Nusantara Sukoharjo, Indonesia
}

\begin{tabular}{|c|c|}
\hline & \multirow{9}{*}{$\begin{array}{l}\text { Abstrac } \\
\text { This study aims to identify the influence of the company's life cycle } \\
\text { and the size of the company on profit management measured using } \\
\text { Discreationary Accruals (DA). The population of this study is } \\
\text { industrial serktor manufacturing companies of consumer goods and } \\
\text { automotive registered in IDX during the Covid-19 pandemic. } \\
\text { Sampling techniques using purposive sampling techniques that there } \\
\text { are } 126 \text { companies. The method used in this study was multiple linear } \\
\text { regressions. The results showed that the life cycle of the company has } \\
\text { a positive and significant effect on profit management, while the size } \\
\text { of the company does not affect profit management. }\end{array}$} \\
\hline & \\
\hline & \\
\hline & \\
\hline & \\
\hline & \\
\hline & \\
\hline & \\
\hline & \\
\hline
\end{tabular}

Sukoharjo

Indonesia

\begin{abstract}
Abstrak
Tujuan dari penelitian ini adalah untuk mengidentifikasi pengaruh siklus hidup perusahaan dan ukuran perusahaan terhadap manajemen laba yang diukur menggunakan Discreationary Accruals (DA). Populasi penelitian ini adalah perusahaan manufaktur serktor industri barang konsumsi dan otomotif yang terdaftar di BEI selama pandemi Covid-19. Teknik pengambilan sampel menggunakan teknik purposive sampling yang terdapat 126 perusahaan. Metode yang digunakan dalam penelitian ini adalah regresi linier berganda. Hasil penelitian menunjukkan bahwa siklus hidup perusahaan berpengaruh positif dan signifikan terhadap manajemen laba, sedangkan ukuran perusahaan tidak berpengaruh terhadap manajemen laba.
\end{abstract}

Email:

gustita.ap@gmail.com

Kata kunci: manajemen laba, siklus hidup perusahaan, dan ukuran perusahaan

\section{PENDAHULUAN}

Perkembangan dunia bisnis saat ini, perusahaan harus menciptakan keunggulan kompetitif dalam bidang usahanya. Oleh karena itu, perusahaan cenderung selalu menunjukkan kinerja yang baik. Besarnya laba yang diperoleh dapat digunakan sebagai salah satu cara untuk mengetahui kinerja keuangan (Astari \& Suryanawa, 2017). Informasi laba yang ada pada laporan keuangan merupakan perhatian utama dalam menaksir kinerja untuk melihat bagaimana pertanggungjawaban manajemen. Hal tersebut mendorong adanya tindakan untuk mengatur laba atau biasa disebut dengan manajemen laba (Agustia \& Suryani, 2018). Beberpa faktor yang menyebabkan adanya manajemen laba, faktor pertama adalah siklus hidup perusahaan. Siklus hidup perusahaan merupakan satu runtutan bertumbuhnya perusahaan melewati sebagian tahap secara berturut-turut (Sasuruw, 2019). Faktor kedua yang dapat mempengaruhi manajemen laba yaitu ukuran perusahaan. Ukuran perusahaan merupakan tolok ukur yang digunakan untuk membuktikan besar kecilnya perusahaan tersebut (Setiawan \& Hariyati, 2018). Penelitian Sasuruw (2019) serta Kusumawati \& Cahyati (2014) mengungkapkan bahwa siklus hidup perusahaan berpengaruh positif terhadap manajemen laba, berbeda dengan penelitian Setiawan \& Hariyati (2018) yang 
mengungkapkan bahawa siklus hidup perusahaan berpengaruh negatif terhadap manajemen laba. Penelitian Astari \& Suryanawa (2017) mengungkapkan bahwa ukuran perusahaan berpengaruh positif terhadap manajemen laba, sedangkan Prasetya \& Gayatri (2016), Mahawyahrti \& Budiasih (2016), Purnama (2017) dan Setiawan \& Hariyati (2018) mengungkapkan bahwa ukuran perusahaan berpengaruh negatif terhadap manajemen laba. Penelitian ini mengacu pada penelitian Sasuruw (2019) mengenai pengaruh siklus hidup perusahaan, ukuran perusahaan dan laverage terhadap manajemen labapada perusahaan industri manufaktur sektor industri dasar dan kimia yang terdaftar di BEI periode 2015-2017. Penelitian lanjutan yang dilakukan peneliti dengan menghapus variabel laverage, karena penelitian sebelumnya laverage tidak berpengaruh terhadap manajemen laba.

\section{METODE}

\section{Populasi dan Sampel}

Populasi yang digunakan dalam penelitian ini adalah perusahaan manufaktur sektor industri barang konsumsi dan otomotif yang terdaftar di Bursa Efek Indonesia dari triwulan 2 sampai 4 tahun 2020 selama pandemi Covid-19. Pemilihan sampel dalam penelitian ini menggunakan metode porposive sampling berdasarkan kriteria sebagai berikut:

a) Perusahaan manufaktur sektor industri barang konsumsi dan otomotif yang terdaftar di Bursa Efek Indonesia periode 2 sampai 4 tahun 2020

b) Perusahaan manufaktur sektor industri barang konsumsi dan otomotif yang melaporkan laporan keuangan pada triwulan 2 sampai 4 tahun 2020 yang berturutturut tidak merugi

c) Perusahaan manufaktur yang memiliki data keuangan sesuai dengan yang dibutuhkan untuk melakukan penelitian

\section{Definisi Operasional dan Pengukuran Variabel}

Variabel Dependen

Manajemen laba dalam penelitian ini diukur menggunakan identifikasi discreationary accruals menggunakan model modifikasi Jones (Dechow, dkk, 1995) yang dapat dihitung melalui 4 tahap sebagai berikut:

a. Menghitung nilai total akrual

$\mathrm{TA}_{\mathrm{it}}=\mathrm{NI}_{\mathrm{it}}-\mathrm{CFO}_{\mathrm{it}}$

b. Menghitung nilai parameter 1,2 dan 3

$\mathrm{TA}_{\mathrm{it}} / \mathrm{A}_{\mathrm{it}-1}=\beta 1\left(1 / \mathrm{A}_{\mathrm{it}-1}\right)+\beta 2\left(\Delta \mathrm{REV}_{\mathrm{it}} / \mathrm{A}_{\mathrm{it}-1}\right)+\beta 3\left(\mathrm{PPE}_{\mathrm{it}} / \mathrm{A}_{\mathrm{it}-1}\right)+\mathrm{e}$

c. Menghitung Non-Discretionary Accrual (NDAC)

$\mathrm{NDA}_{\mathrm{it}}=\beta 1\left(1 / \mathrm{A}_{\mathrm{it}-1}\right)+\beta 2\left(\Delta \mathrm{REV}_{\mathrm{it}}-\Delta \mathrm{REC}_{\mathrm{it} /} \mathrm{A}_{\mathrm{it}-1}\right)+\beta 3\left(\mathrm{PPE}_{\mathrm{it}} / \mathrm{A}_{\mathrm{it}-1}\right)+\mathrm{e}$

d. Menghitung Discretionary Accrual

$\mathrm{DA}_{\mathrm{it}}=\mathrm{TA}_{\mathrm{it}} / \mathrm{TA}_{\mathrm{it}-1}-\mathrm{NDA}_{\mathrm{it}}$

Variabel Independen

Siklus hidup perusahaan

Tahapan siklus hidup perusahaan dalam penelitian ini hanya menggunakan tiga tahapan yaitu tahap growth, mature, dan decline. Siklus hidup perusahaan diukur menggunakan arus kas karena dianggap lebih sesuai dibandingkan proksi lain. Berikut kriteria untuk mengklasifikasikan perusahaan: 


\begin{tabular}{llll}
\multicolumn{4}{l}{ Tabel 1. Siklus Hidup Perusahaan Metode Arus kas } \\
\hline Arus Kas & Growth & Mature & Decline \\
\hline Arus Kas Operasional & + & + & - \\
Arus Kas Investasi & - & - & + \\
Arus Kas Pendanaan & + & - & $+/-$ \\
\hline
\end{tabular}

Selanjutnya memasukkan setiap tahapan perusahaan kedalam skala interval. Pada tahap siklus hidup perusahaan menggunakan angka 1 untuk tahap growth, angka 2 untuk tahap mature, angka 3 untuk tahap decline, dan angka 0 untuk perusahaan yang tidak termasuk dalam tahapan siklus hidup perusahaan

\section{Ukuran Perusahaan}

Ukuran perusahaan menggunakan tolok ukur total aset dengan cara merubah ke dalam pola logaritma natural. Ukuran perusahaan diukur dengan rumus sebagai berikut: Ukuran perusahaan $=$ Ln $($ Total Aset $)$

$$
\mathrm{DA}=\alpha+\beta 1 \mathrm{SHP}-\beta 2 \mathrm{SIZE}+\mathrm{e}
$$

DA : Manajemen laba

SHP : Siklus Hidup Perusahaan

Size : Ukuran Perusahaan

\section{HASIL}

Tabel 2. Sampel Penelitian

\begin{tabular}{ll}
\hline Sampel Berdasarkan Kriteria Kriteria & Jumlah \\
\hline $\begin{array}{l}\text { Perusahaan manufaktur sektor sektor industri barang konsumsi } \\
\text { dan otomotif }\end{array}$ & 64 \\
$\begin{array}{l}\text { Perusahaan manufaktur sektor industri dan otomotif dengan } \\
\text { laporan keuangan lengkat triwulan 2-4 periode 2020 }\end{array}$ & 62 \\
$\begin{array}{l}\text { Perusahaan manufaktur sektor industri barang konsumsi dan } \\
\text { otomotif yang berturut-turut tidak merugi selama penelitian }\end{array}$ & 42 \\
$\begin{array}{l}\text { Jumlah data (42 x 3) } \\
\text { Data outlier }\end{array}$ & 126 \\
Jumlah sampel data & $(8)$ \\
\hline
\end{tabular}

Sumber: Data yang telah diolah, 2021

Tabel 3. Statistik Deskriptif

\begin{tabular}{llllll}
\hline & N & Minimum & Maximum & Mean & Std. Deviation \\
\hline $\begin{array}{l}\text { Manajemen Laba } \\
\text { Siklus Hidup }\end{array}$ & 118 &,- 030 &, 040 &, 00169 &, 012897 \\
$\begin{array}{l}\text { Perusahaan } \\
\text { Ukuran Perusahaan }\end{array}$ & 118 & 0 & 2 & 1,34 &, 819 \\
Valid N (Listwise) & 118 & 25,510 & 33,470 & 28,9789 & 1,725985 \\
Suld & 118 & & & 0 & \\
\hline
\end{tabular}

Sumber: data yang telah diolah, 2021

Tabel 4. Koefisien Determinasi ( $\mathbf{R}^{2} / \mathbf{R}$ Square)

\begin{tabular}{lllll}
\hline Model & $\boldsymbol{R}$ & $\boldsymbol{R}$ Square & $\begin{array}{l}\text { Adjusted } \boldsymbol{R} \text { Std. Error of } \\
\text { Square }\end{array}$ & $\begin{array}{l}\text { Esthe Estimate } \\
\text { the }\end{array}$ \\
\hline 1 &, $232^{\mathrm{a}}$ &, 054 &, 037 &, 012653 \\
\hline
\end{tabular}

Sumber: data yang telah diolah, 2021 
Tabel 5. Signifikasi Simultan (Statistik F)

\begin{tabular}{|c|c|c|c|c|c|}
\hline Model & $\begin{array}{l}\text { Sum } \\
\text { Squares }\end{array}$ & of $D f$ & Mean Square & $F$ & Sig. \\
\hline Regression & 001 & 2 & ,001 & 3,275 &, $041^{\mathrm{b}}$ \\
\hline 1 Residual & ,018 & 115 &, 000 & & \\
\hline Total & 019 & 117 & & & \\
\hline
\end{tabular}

Sumber: data yang telah diolah, 2021

Tabel 6. Signifikasi Parameter Individual (Statistik T)

\begin{tabular}{llllll}
\hline Model & \multicolumn{2}{l}{$\begin{array}{l}\text { Unstandardized } \\
\text { Coefficients } \\
\text { B }\end{array}$} & $\begin{array}{l}\text { Standardized } \\
\text { Coefficients }\end{array}$ & T & Sig. \\
& Beta & & \\
\hline (Constant) &, 006 &, 020 & &, 295 &, 768 \\
Siklus Hidup Perusahaan &, 004 &, 001 &, 235 & 2,558 &, 012 \\
Ukuran Perusahaan &, 000 &, 001 &,- 042 &,- 456 &, 649 \\
\hline
\end{tabular}

Sumber: data yang telah diolah, 2021

Pengujian Hipotesis Pertama

H1: Siklus hidup perusahaan (SHP) berpengaruh positif terhadap manajemen laba (DA)

Tabel IV.12 uji statistik $\mathrm{t}$ diatas menunjukkan bahwa nilai signifikasi pengaruh variabel siklus hidup perusahaan (SHP) terhadap variabel manajemen laba (DA) sebesar 0,012 lebih kecil dari 0,050. Hal tersebut berarti bahwa SHP berpengaruh signifikan terhadap DA. Nilai thitung variabel siklus hidup perusahaan sebesar 2,558 yang berarti bahwa siklus hidup perusahaan berpengaruh positif terhadap manajemen laba. Sehingga hipotesis yang menyatakan bahwa siklus hidup perusahaan berpengaruh positif terhadap manajemen laba dapat diterima, maka penelitian ini menerima hipotesis 1.

Pengujian Hipotesis Kedua

H2: Ukuran perusahaan (SIZE) berpengaruh negatif terhadap manajemen laba (DA)

Tabel IV.11 uji statistik $\mathrm{t}$ diatas menunjukkan bahwa nilai signifikasi pengaruh variabel ukuran perusahaan (SIZE) terhadap manajemen laba (DA) sebesar 0,649 lebih besar dari 0,050 . Hal tersebut berarti bahwa UP tidak berpengaruh signifikan terhadap DA. Sehingga hipotesis yang menyatakan bahwa ukuran perusahaan berpengaruh negatif terhadap manajemen laba tidak dapat diterima, maka penelitian ini menolak hipotesis 2 .

\section{PEMBAHASAN}

Pengaruh siklus hidup perusahaan terhadap manajemen laba

Hasil pengujian pengaruh siklus hidup perusahaan terhadap manajemen laba pada penelitian ini menunjukkan bahwa siklus hidup perusahaan berpengaruh positif terhadap manajemen laba pada perusahaan yang diteliti. Hasil tersebut sesuai dengan hipotesis yang peneliti ajukan, sehingga hipotesis 1 diterima. Hal tersebut dikarenakan semakin tinggi tahapan perkembangan perusahaan maka semakin tinggi perusahaan melakukan praktik manajemen laba, hal tersebut dilakukan karena pada saat tahap berkembang perusahaan harus bisa memperlihatkan laba yang stabil bahkan tinggi agar para investor tertarik pada perusahaan tersebut. Pada saat perusahaan tersebut berada pada tahap 
merosot manajemen harus melakukan praktik manajemen laba agar perusahaan tidak mengalami kebangkrutan.

\section{Pengaruh ukuran perusahaan terhadap manajemen laba}

Hasil pengujian pengaruh ukuran perusahaan terhadap manajemen laba pada penelitian ini menunjukkan ukuran perusahaan tidak berpengaruh terhadap manajemen laba pada perusahaan yang diteliti. Hasil tersebut tidak sesuai dengan hipotesis yang peneliti ajukan, sehingga hipotesis kedua ditolak. Hasil tersebut dikarenakan adanya perlindungan yang ketat dari penanam modal dan pemerintah yang ikut mengoperasikan perusahaan. Perlindungan yang ketat tersebut akan menghalangi manajer dalam memanfaatkan manajemen laba karena besar kemungkinan akan terbongkar.

\section{SIMPULAN}

Kesimpulan pada penelitian ini berdasarkan hasil penelitian dan pembahasan yang peneliti lakukan di bab sebelumnya

a. Siklus hidup perusahaan berpengaruh positif signifikan terhadap manajemen laba. Hasil penelitian ini menerima hipotesis

b. Ukuran perusahaan tidak berpengaruh signifikan terhadap manajemen laba. Hasil penelitian ini menolak hipotesis

\section{DAFTAR PUSTAKA}

Agustia, Y, O., \& Suryani, E. (2018). Pengaruh Ukuran Perusahaan, Umur Perusahaan, Laverage, dan Profitabilitas terhadap Manajemen Laba. JOM Fekon, 3(1).

Ali, U. (2015). Impact of Firm Size on Earnings Management; A Study of Textile Sector of Pakistan. 7(28), 47-56.

Astari, A, A, M, R., \& Suryanawa, I, K. (2017). FAktor-Faktor Yang Mempengaruhi Manajemen Laba Fakultas Ekonomi dan Bisnis Universitas Udayana ( Unud), Bali, Indonesia Fakultas Ekonomi dan Bisnis Universitas Udayana ( Unud ), Bali , Indonesia ABSTRAK Perkembangan dalam dunia bisnis sekarang ini telah. 20, 290-319.

Astuti, A, Y., Nuraina, E., dan Wijaya, A, L. (2017). The 9 th FIPA. Pengaruh Ukuran Perusahaan Dan Leverage Terhadap Manajemen Laba, 5(1), 399-417.

Hastuti, T. (2017). Polish Journal Of Management Studies The Effect Of Company Life Cycles On The Accruals Earnings Management With Internal Earnings Management With Internal Control. July. https://doi.org/10.17512/pjms.2017.15.1.07

https://industri.kontan.co.id/news/ikut-terdampak-corona-surya-toto-toto-pasang-targetkonservatif-tahun-ini 8 sept 202016.44 diakses pada 31 jan 202122.00

https://investasi.kontan.co.id/news/bergerak-tidak-wajar-bursa-awasi-saham-muliaindustrindo-mlia 19 nov 2020 dikses 2 januari 2021

https://otomotif.kompas.com/read/2020/07/31/132200615/astra-juga-terdampakpandemi-laba-bersih-anjlok-semester-i-2020 31 juli 2020 diakses 26 desember 2020

https://www.bkpm.go.id/id/publikasi/detail/berita/bkpm-eksekusi-investasi-mangkrakdi-tengah-pandemi-covid-19, 1 Juli 2020 diakses pada 2 Januari 2021

https://www.cnbcindonesia.com/market/20201207111049-17-207303/ada-pandemicovid-laba-eks-holcim-melesat-120-jadi-rp-438-m 7 desember 2020, diakses 29 desember 2020

Kusumawati, E., \& Cahyati, A. D. (2014). Perusahaan Terhadap Earning Management. 5(1), 53-74.

Machdar, N. M. (2018). Pengaruh Manajemen Laba Akrual dan Manajemen Laba Riil 
Terhadap Nilai Perusahaan dengan Good Corporate Governance Sebagai Variabel Moderating. October 2017.

Mahawyahrti, T., \& Budiasih, G. N. (2017). Asimetri Informasi, Leverage, dan Ukuran Perusahaan pada Manajemen Laba. Jurnal Ilmiah Akuntansi Dan Bisnis, 11(2), 100. https://doi.org/10.24843/jiab.2016.v11.i02.p05

Medyawati, H., \& Dayanti, A. (2016). Pengaruh Ukuran Perusahaan Terhadap Manajemen Laba: Analisis Data Panel. Jurnal Ilmiah Ekonomi Bisnis, 21(3), 96409. https://doi.org/10.35760/eb.

Pebrianti, Y. (2017). Siklus Hidup Perusahaan Dan Teori Pecking Order.I-Economic. $3(4)$.

Prasetyo, P, J., \& Gayatri.(2016). Pengaruh Ukuran Perusahaan Terhadap Manajemen Laba Dengan Pengungkapan Corporate Social Responsibility Sebagai Variabel Intervening. E-Jurnal Akuntasi Universitas Udayana. 14(1).

Purnama, D. (2017). Pengaruh Profitabilitas, Leverage, Ukuran Perusahaan, Kepemilikan Institusional Dan Kepemilikan Manajerial Terhadap Manajemen Laba. Jurnal Riset Keuangan Dan Akuntansi, 3(1), 1-14. https://doi.org/10.25134/jrka.v3i1.676

Sasuruw, F. A. (2019). Pengaruh Siklus Hidup Perusahaan, Ukuran Perusahaan Dan Leverage Terhadap Manajemen Laba. Fiolinta Afdina Sasuruw Jurusan Akuntansi , Fakultas Ekonomi , Universitas Negeri Surabaya. Jurnal Akuntansi Unesa, 8(1).

Setiawan, A., \& Hariyati.(2018). Pengaruh Siklus Hidup Perusahaan Terhadap Manajemen Laba Dengan Corporate Governance Sebagai Variabel Mediasi. Journal of Materials Processing Technology, 1(1), 1-8.

Ghozali, Imam. 2013. Aplikasi Analisis Multivariate dengan Program IBM SPSS 21 Update PLS Regresi.Semarang: Badan Penerbit Universitas Diponegoro.

Sugiyono. 2017. Metode Penelitian Pendidikan.Bandung: ALFABETA.

Sulistyanto (e.d). 2008. Manajemen Laba Teori dan Model Empiris. Jakarta: PT Glasindo. 